\title{
ANALYSIS OF COMPRESSED NATURAL GAS BURN RATE AND FLAME PROPAGATION ON A SUB-COMPACT VEHICLE ENGINE
}

\author{
${\text { Devarajan } \operatorname{Ramasamy}^{1 *} \text {, K. Kadirgama }}^{1}$, M.M. $\operatorname{Rahman}^{1}$ and Z.A. Zainal ${ }^{2}$ \\ ${ }^{1}$ Faculty if Mechanical Engineering, Universiti Malaysia Pahang \\ 26600 Pekan, Pahang, Malaysia \\ ${ }^{2}$ USM School of Mechanical Engineering, \\ Engineering Campus, Universiti Sains Malaysia, Seri Ampangan, \\ 14300 Nibong Tebal, Seberang Perai Selatan, Pulau Pinang, Malaysia \\ *Email: deva@ump.edu.my
}

\begin{abstract}
In terms of sub-compact cars using alternative fuels, the vehicle characteristics are governed by the engine operation. The main focus of this paper was to evaluate a subcompact car engine on its performance and burn rate of gasoline and compressed natural gas $(\mathrm{CNG})$. A bi-fuel sequential system was used for this evaluation. Measurements of engine speed, torque and fuel were done on an eddy current dynamometer, while measurements of in-cylinder pressure, crank angle and spark were analyzed from results taken by a data acquisition system. The emissions readings were also compared using an emission analyzer. The results were analyzed for burn rate based on the first law of thermodynamics. A 3-dimensional computational fluid dynamics (CFD) model was done to estimate the flame speed. The comparison shows an average drop of $18.6 \%$ for the power, $7 \%$ for brake specific fuel consumption (BSFC) and the efficiency loss was $17.3 \%$. Pressure analysis shows peak pressure dropped by $16 \%$. The burn rate shows why CNG had a slower burning speed on the small engine. CFD predicted the flame propagation speed at $8.45 \mathrm{~m} / \mathrm{s}$. The engine speed of $4000 \mathrm{rpm}$ at maximum brake torque produced the results nearest to those for gasoline. In conclusion, volumetric losses and CFD errors slightly reduce the accuracy of the results, but nevertheless an $8.45 \mathrm{~m} / \mathrm{s}$ flame speed was estimated.
\end{abstract}

Keywords: Bi-fuel; natural gas; burn rate; engine testing; flame speed.

\section{INTRODUCTION}

A sub-compact vehicle is a vehicle which has between $2407 \mathrm{~L}$ and $2803 \mathrm{~L}$ of interior volume according to the US Environmental Protection Agency [1]. Usually, it has a length of $4191 \mathrm{~mm}$ but is longer than a micro car [2]. Such cars are usually popular in the South-East Asian region. This is because the majority of South-East Asian people lives in cities which require a small and high manoeuvrability vehicle without compromising interior volume. Normally, the sub-compact vehicle is powered by an internal combustion engine (ICE) [3]. ICEs rely on fossil fuel such as gasoline and diesel [4]. Fossil fuel is a non-renewable energy source which implies that there is a finite amount in the world [5-8]. Also, when fossil fuel burns, it produces pollutants such as carbon dioxide which will contribute to the greenhouse effect, nitrous oxide which contributes to acid rain, and others [9]. Therefore, the study of vehicle efficiency is important for this class of car. Energy consumption is continuously increasing, and 
the use of petroleum as one of the main sources of energy is leading to fuel depletion in many countries around the world [10]. The proven reserves may last up to 40-50 years only, and the current vehicle production is ever-increasing. From 700 million vehicles in 2001 , the number of vehicles increased more than tenfold to about a billion vehicles worldwide, with $3 \%$ average of annual growth [11]. As vast amounts of petroleum are used in the transportation sector, many alternatives have appeared, such as electric vehicles, bio- fuels, solar energy, natural gas (NG), wind, and also liquefied petroleum gas (LPG) [4, 12]. Alternative fuels have been introduced in vehicle applications for the past few decades to reduce both petroleum consumption and exhaust emissions. Of these alternatives, only natural gas in the form of compressed natural gas (CNG) and LPG appear to be more economic and worthy of implementation on vehicles [11, 13].

Comparing CNG to LPG, the relative abundance and lower price of CNG has resulted in its increased usage as a vehicular fuel currently and in the near future, as reported by Ramasamy, Bakar [14]. CNG fuel has proven deposits that can last more than 66 years [15]. The fuel also has good environmental impacts, which is another worldwide concern. Vehicle conversion to CNG is automatically EURO-1 compliant and has further possibilities to satisfy California's program for low emission vehicles (LEV), ultra-low emission vehicles (ULEV), and zero emission vehicles (ZEV). The use of CNG has shown reductions in emissions of carbon monoxide (CO) by 90-97\%, carbon dioxide $\left(\mathrm{CO}_{2}\right)$ by $25 \%$, nitrous oxide (NOx) by 35-60\%, and non-methane hydrocarbon (NMHC) by 50-75\%) [16]. In the context of developing countries in the Asia-Pacific region, Malaysia's role as an oil-producing country has been slowly reducing. Consequently, the petroleum price in Malaysia has increased due to high demand in the world market. According to Figure 1, Malaysian petroleum production peaked in 2005 but will continue to become scarce by 2015[17].

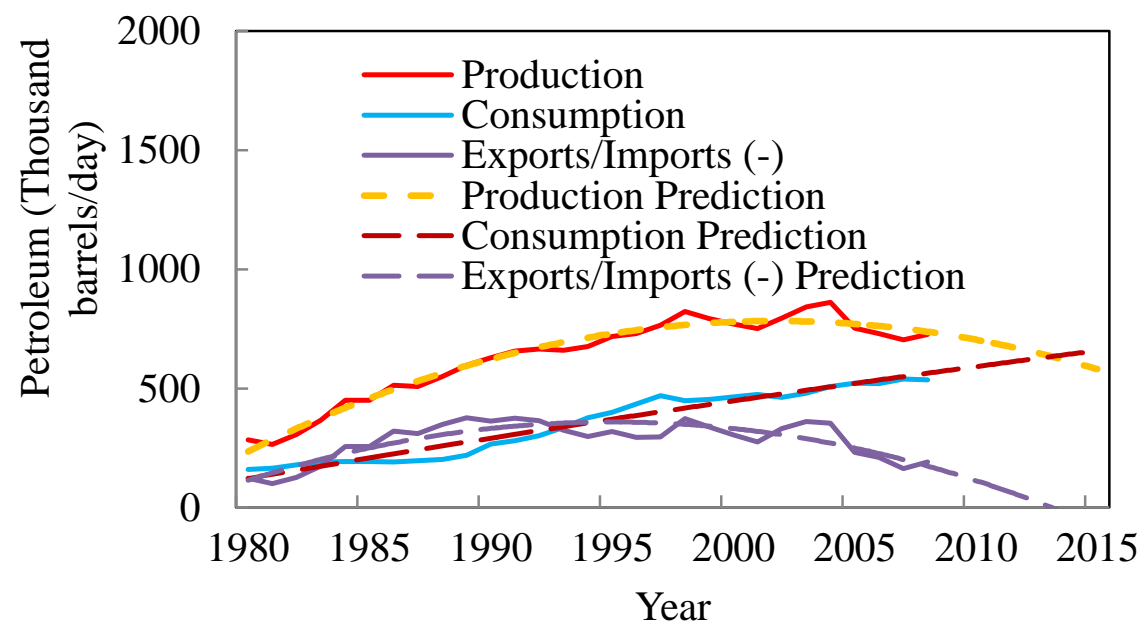

Figure 1. Petroleum production in Malaysia[17].

In another context, the trend of production of NG in Malaysia is shown in Figure 2. There was a steady growth of NG fuel production as compared to petroleum. From the perspective of an oil-producing country such as Malaysia, the price of petrol was at MYR 2.10 per liter and the price of NG in the form of CNG was MYR 0.68 per liter equivalent, a $65 \%$ cost difference. The current practice of CNG fuel delivery has been via port injection, making bi-fuel systems plug and play on most readily available petrol engines. Although studies suggest that direct injection may be the future fuel 
delivery of choice for CNG, port injected bi-fuel systems can be a cost-effective match for most of the existing engines in use [18]. As CNG usage grows, the understanding and control of its combustion in a petrol bi-fuel engine is crucial to get the best efficiency, power and range [11]. The CNG engine has been found to have losses when implemented on a gasoline engine. Losses in terms of power, brake specific fuel consumption and engine efficiency relate to in-cylinder burning of the fuel. A CFD analysis also shows how much flame speed is lost in the cylinder of the CNG engine. As such, both angles are required to benchmark a sub-compact engine. The focus of this paper is to find the extent of losses incurred on a bi-fuel sub-compact car engine.

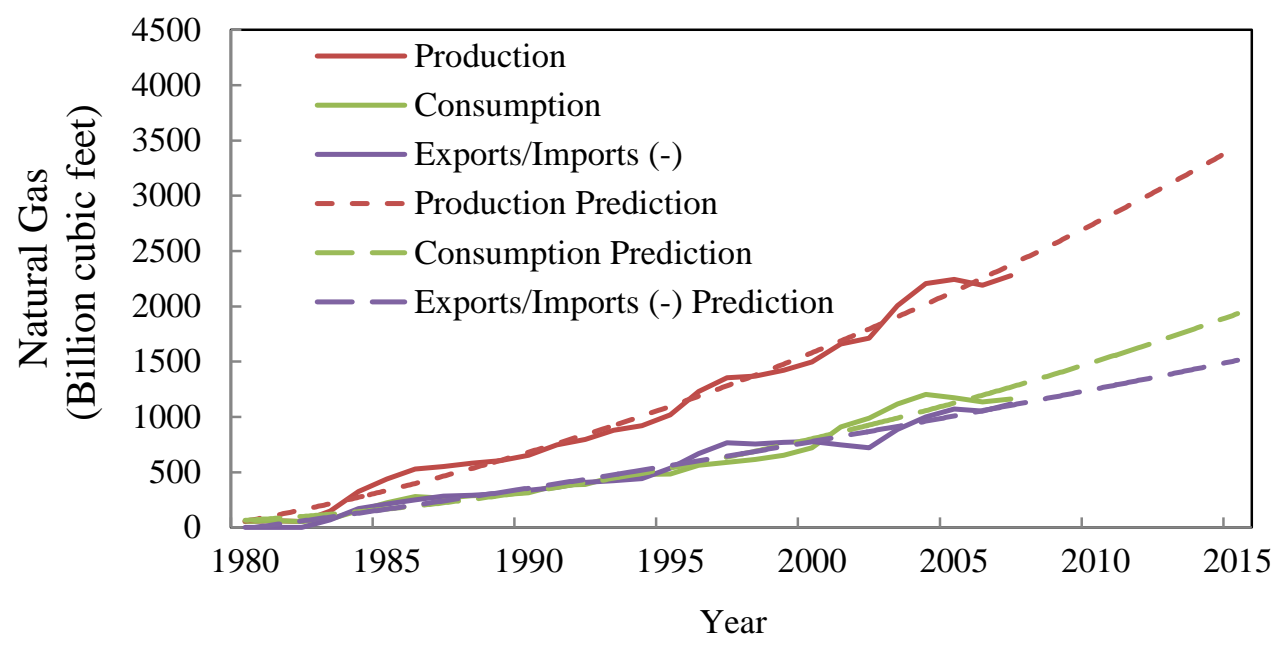

Figure 2. Natural gas production, consumption and exports in Malaysia[17].

\section{COMPUTATIONAL FLUID DYNAMICS MODEL}

For ICE simulation, the governing equation of fluid flow was written by [19],

1. Continuity equation:

$$
\frac{\partial \rho}{\partial t}+\nabla \cdot \rho v=\mathrm{S}_{\mathrm{m}}
$$

where $\rho$ is the density, $\mathrm{v}$ is the volume, $\mathrm{S}_{\mathrm{m}}$ is the mass added to the continue phase from the dispersed second phase.

Eq. (1) is a general form of continuity equation and can be used for either compressible or incompressible flow. $S_{m}$ is the mass added to the continue phase from the dispersed second phase.

2. Momentum equation:

$$
\frac{\partial}{\partial t}(\rho v)+\nabla \cdot(\rho v v)=-\nabla p+\nabla \cdot \tau+\rho g+F
$$

where $p$ is static pressure, $\tau$ is stress sensor, and $p g$ and $F$ are the gravitational body force and external body force respectively. 
3. Energy equation:

$$
\frac{\partial}{\partial t}(\rho E)+\nabla \cdot(v(\rho E+p))=\nabla\left(k_{e f f} \nabla T-\sum_{j} h_{j} J_{j}+\tau_{e f f} \cdot v\right)+S_{h}
$$

where $E$ is internal energy, $k_{e f f}$ is the effective conductivity and $J_{j}$ is the diffusion flux of species $j . S_{h}$ includes the heat of chemical reaction and other volumetric heat sources.

With respect to dynamic meshes, the conservation equation of the moving boundary can be written as;

$$
\frac{d}{d t} \int_{v} \rho \emptyset d v+\int_{\partial v} \rho \emptyset\left(u-u_{g}\right) d A=\int_{\partial v} C \nabla \emptyset d A+\int_{v} s_{\varnothing} d v
$$

where $\rho$ is fluid density, $u$ is the flow velocity vector, $u_{g}$ is mesh velocity of moving mesh, $C$ is the diffusion coefficient, $s_{\varnothing}$ is a source term of generative scalar, $v$ is control volume, $\partial v$ is boundary of control volume.

The model was developed from the engine parameters shown in Table 1 . The volume of the combustion chamber was scanned using a laser scanner and intake length was measured.

Table 1. Engine specification.

\begin{tabular}{lc}
\hline Parameter & Specification \\
\hline Engine type & K3-VE \\
Valve mechanism & DOHC, 16V with DVVT \\
Total displacement & $1298 \mathrm{cc}$ \\
Bore X stroke & $72.0 \times 79.7 \mathrm{~mm}$ \\
Compression ratio & $10.0: 1$ \\
Maximum power output & $67 / 6000 \mathrm{~kW} / \mathrm{rpm}$ \\
Maximum torque output & $117 / 4400 \mathrm{Nm} / \mathrm{rpm}$ \\
Fuel system & Electronic fuel injection \\
\hline
\end{tabular}

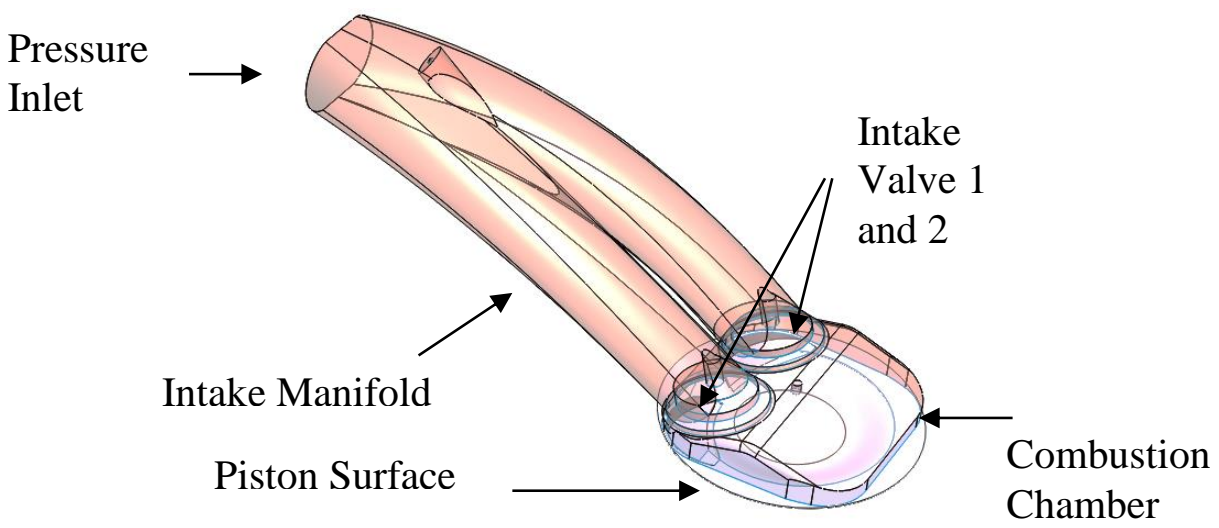

Figure 3. CFD Boundary conditions.

Figure 3 shows the boundary created for the CFD analysis. The model was discretized to solve the CFD equations using a hybrid mesh approach. Two types of elements were used to develop the hybrid mesh as shown in Figure 4. One is a 
tetrahedral mesh for the complex combustion chamber shape, and the other is a quadrilateral mesh for the moving parts (dynamic mesh zone). The piston surface and valve opening used the layering mesh method to move the mesh.

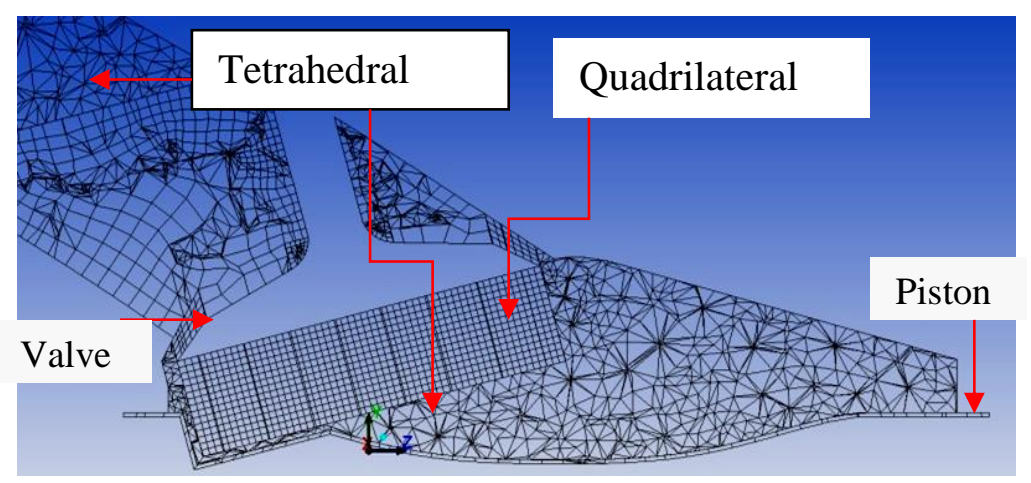

Figure 4. Hybrid mesh of the intake manifold, intake valve, combustion chamber and piston.

\section{EXPERIMENT DETAILS}

The vehicle chosen for testing is a sub-compact car from Malaysia. The car engine is as shown in Figure 5. The engine tests were conducted on a test cell which was connected by various sensors.

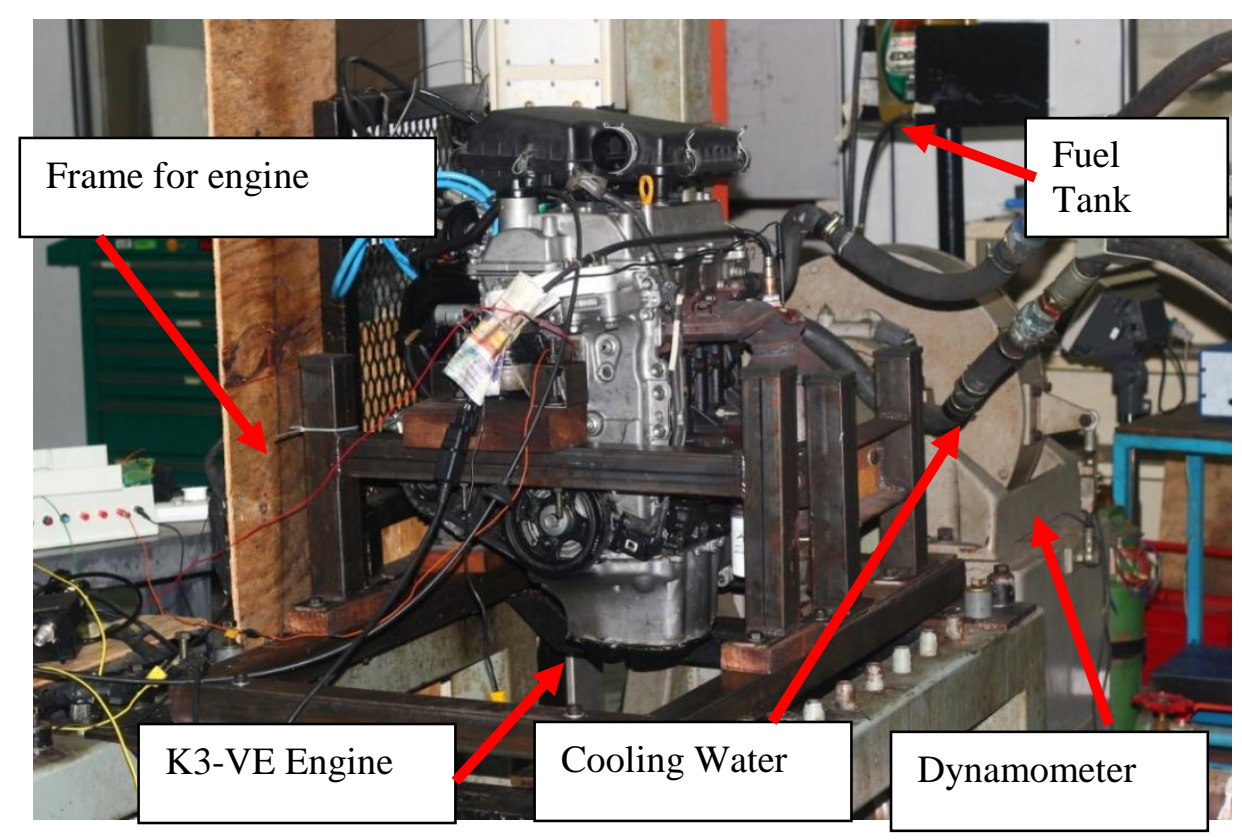

Figure 5. Engine testing setup for the sub-compact engine.

The engine was connected to a crank encoder for a $1^{\circ}$ angle crank angle measurement, pressure measurement using Kistler 6052C and charge amplifier, a dynamometer for torque measurement, a fuel scale measuring weight, $1 \mathrm{~g}$ resolution, throttle measurement using a throttle position sensor (TPS), and an emissions analyzer (KANE $\left.{ }^{\mathrm{TM}}\right)$. The sensors were integrated by using a data acquisition system, Agilent 
U2542A. It features four simultaneous analog input channels with sampling rates up to 500,000 samples per second $(\mathrm{Sa} / \mathrm{sec})$ [20]. Two types of experimental testing were conducted in this research:

1. Performance test: to measure the power, torque and fuel consumption of the engine.

2. Pressure traces measurement: to analyze the pressure wave action in the manifold.

In order to compare the engine performance on a common basis, tests were run at standard conditions. Whenever this was not possible, a correction factor was applied to the measured torque value to account for the difference between the actual inlet air condition and standard air condition [21].

\section{RESULTS AND DISCUSSION}

Engine power was compared to CNG in Figure 6. The CNG fuel has overall power loss, as suggested by Pourkhesalian, Shamekhi [22]. The power loss occurs as mentioned before, due to the lesser volumetric efficiency of CNG. These losses can be regained by increasing the turbulence of the airflow to pack in more air [23]. The most significant volumetric losses need to be addressed, so the future design of engines using CNG needs to include more turbulence. Brake specific fuel consumption (BSFC) measured and compared to gasoline shows that $\mathrm{CNG}$ and gasoline fuel are very similar to each other, as shown in Figure 7. However, a slight increase of fuel consumption occurs at low engine speeds of $1000 \mathrm{rpm}$ and $2000 \mathrm{rpm}$, and also during peak operation of 6000 rpm. The low speed loss occurs due to the improper idling of the engine and tuning[24], which occur because the engine was designed for gasoline and the CNG system used lacks tuning across the whole of the engine range[25].

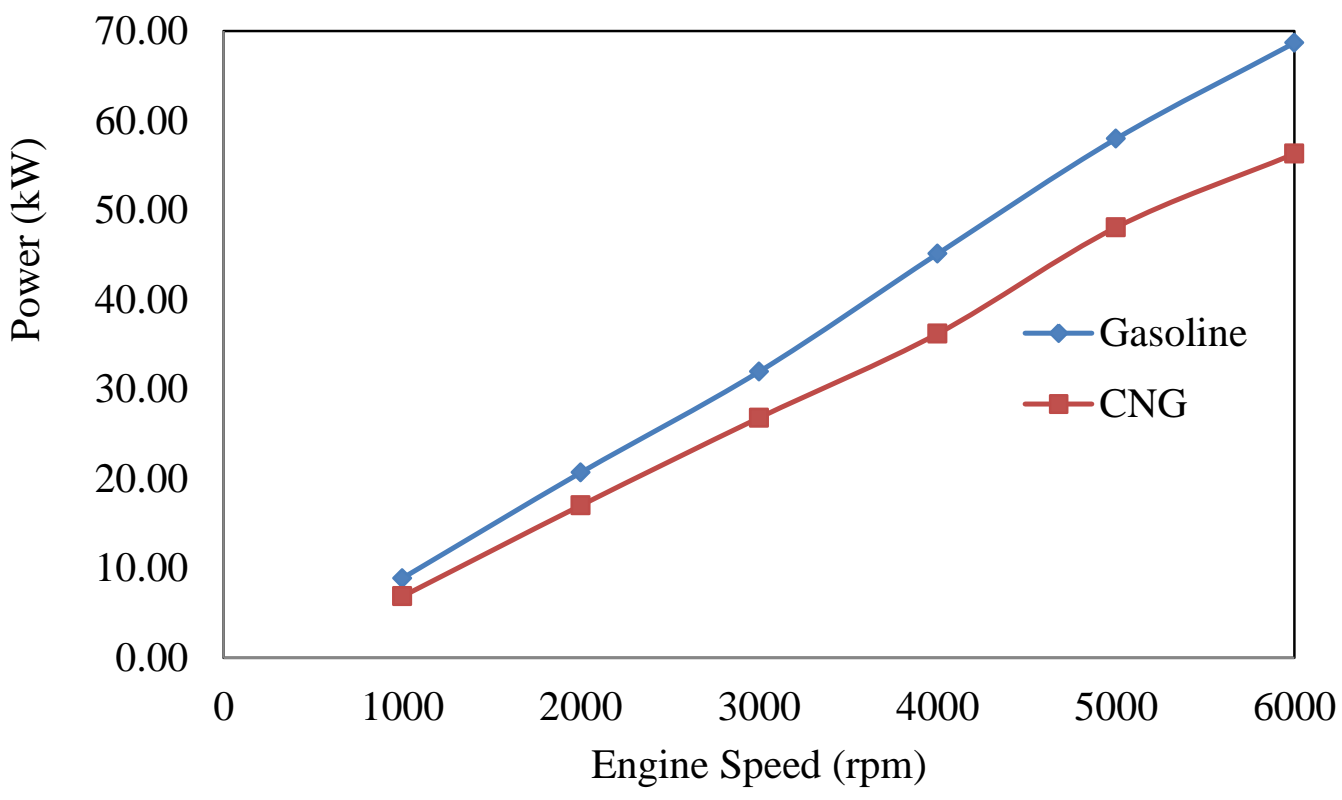

Figure 6. Engine power against engine speed. 


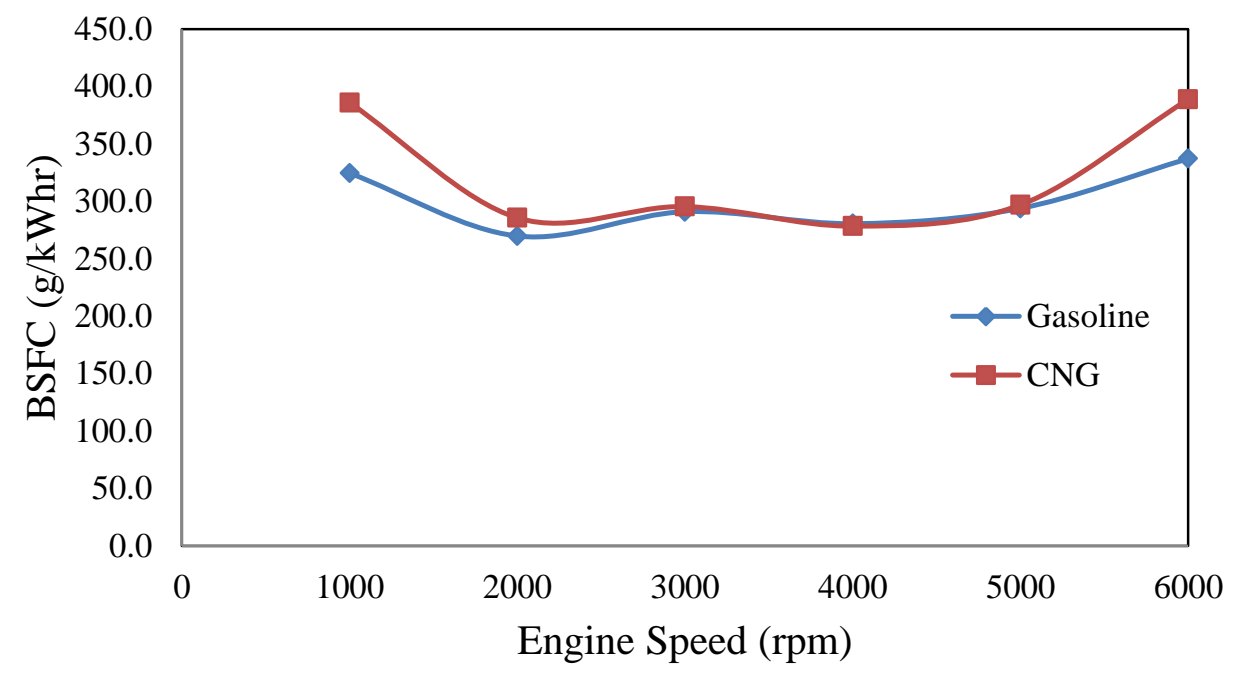

Figure 7. BSFC against engine speed.

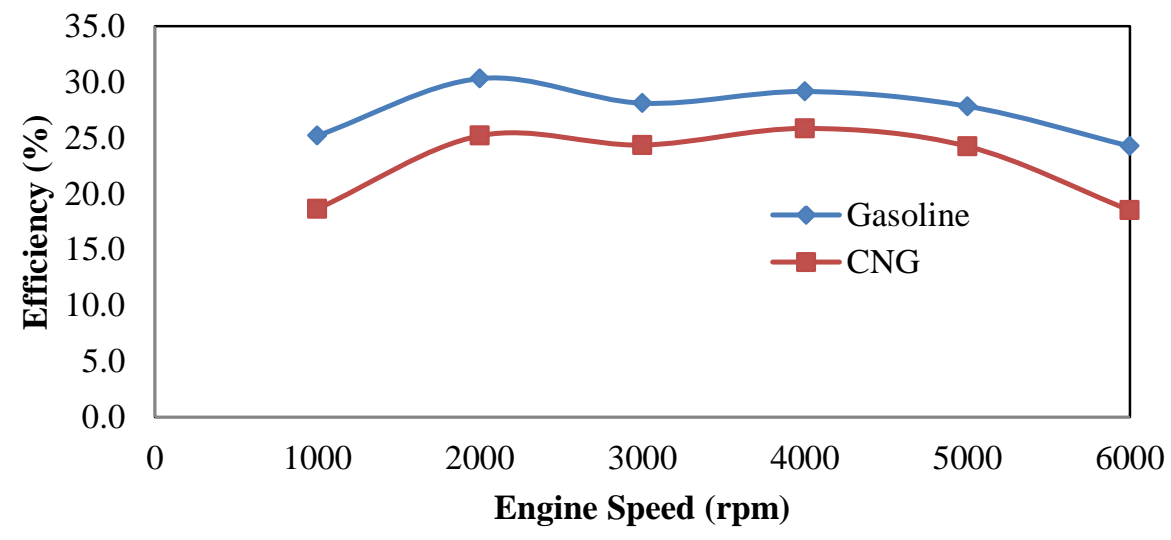

Figure 8. Engine efficiency against engine speed.

Installation of the CNG kit only takes into account one point to calibrate the gaseous injector signal, which may be insufficient for the entire engine operation. Overall engine efficiency suffered loss in the whole engine speed range, as shown in Figure 8 . An average loss of $17.3 \%$ is seen from the efficiency curve. This shows that tuning of the gasoline engine is still lacking when running on CNG gas. The gas exhaust temperatures of gasoline and $\mathrm{CNG}$ are shown in Figure 9, where the temperature was constant except at $6000 \mathrm{rpm}$. The gas temperature increased by almost $100^{\circ} \mathrm{C}$. The engine temperature increases at 4000-6000 rpm. This is due to the slow burning of the CNG, which was still burning when the exhaust valve was opening[26]. Hence, this releases a lot of heat into the exhaust. There is the potential for valve failure if the engine is driven for a long period of time at a high engine speed. This happens if the hotter exhaust gas hits the exhaust valve and burns it. In the engine life cycle, the material of the valve is exposed to constantly varying temperatures which may cause it to wear [27]. 


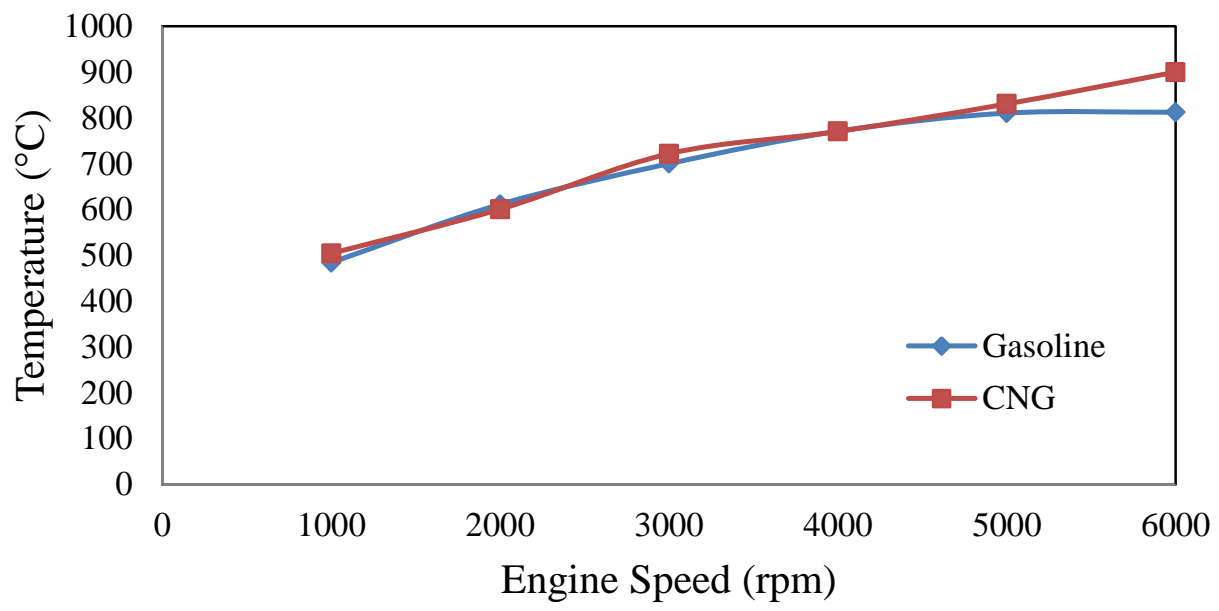

Figure 9. Exhaust gas temperature vs engine speed.

In terms of emissions, referring to Figure 10, hydrocarbon (HC) levels are very low compared to gasoline. $\mathrm{HC}$ registered on average a $78 \%$ reduction due to the lower carbon content in the $\mathrm{CNG}$, which has only one carbon to four hydrogen atoms $\left(\mathrm{CH}_{4}\right)$. However, nitrous oxide (NOx) was increased by 67\%. Again, this shows that the CNG was burning late, as it creates more thermal NOx due to hot exhaust. The larger temperature gradient during exhaust opening is the cause of this.

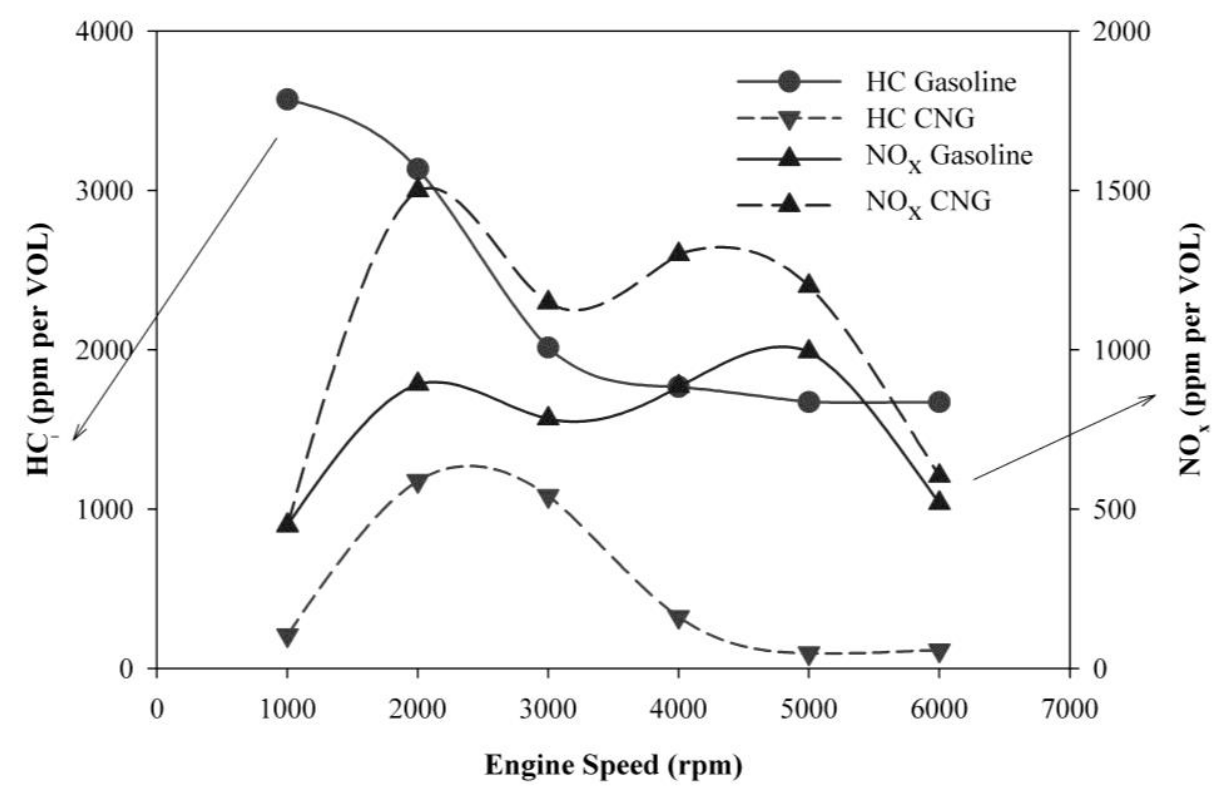

Figure 10. Exhaust emissions against engine speed.

As the engine speed increases to the maximum, the pressure trace distorts to the right (after TDC) as in Figure 11(a). This shows that the ignition system was also affected by the slow burning. The spark given by the conventional bi-fuel system was not enough to burn the CNG at high engine speed. The peak pressure occurred $20^{\circ}$ after TDC, signalling a tendency for knock to occur. Also this was the reason that the engine and exhaust temperature increased, as the bulk of the burnt gasses occur later during the expansion stroke, causing the valve to be heated by the hot outgoing gasses[28]. In the 
same instance, the mass fraction burn has a lower gradient due to the engine's high speed operation, as seen in Figure 11(b), indicating a slower flame speed.

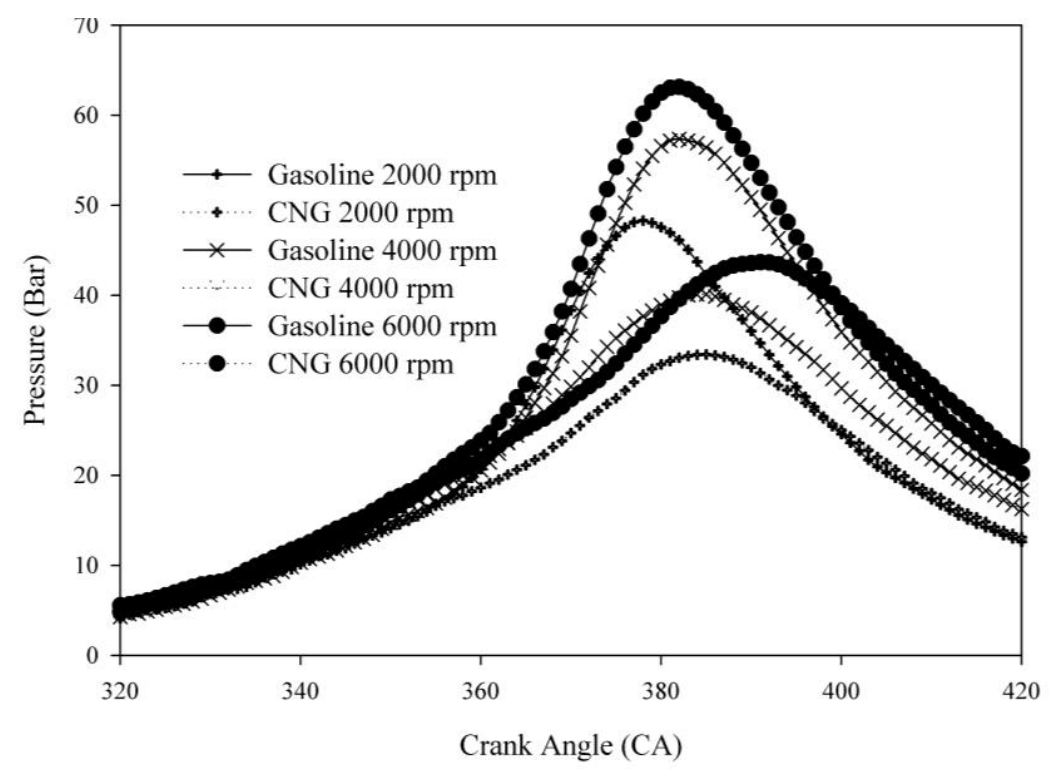

(a)

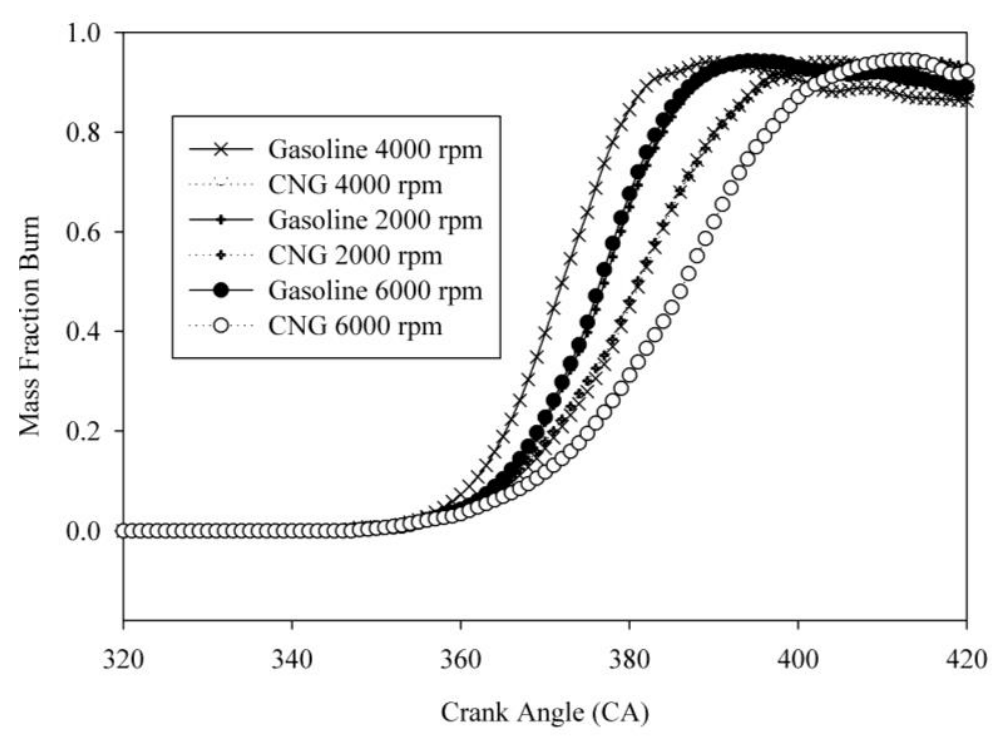

(b)

Figure 11. Combustion pressure versus engine speed.

The CFD model was used to estimate the flame propagation speed model. The side view of the CFD simulation is measured for the temperature contour and from the crank angle the time is measured. With these two sets of data, the flame is measured for CNG. The flame makes a $70^{\circ}$ angle due to the turbulence induced by the cylinder, as shown in Figure 12. During combustion the flame is seen moving from the flow trajectories in the $70^{\circ}$ angle. The flame measured $8.45 \mathrm{~m} / \mathrm{s}$ as the average time taken to hit the wall and quench. This value was estimated from the point of spark location at $340^{\circ}$ BTDC to the first point at which the flame touches the wall of the combustion 
chamber at $10^{\circ}$ ATDC to quench. The length and time are used to calculate the flame speed[29].

$340^{\circ} \mathrm{BTDC}$

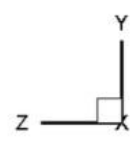

$350^{\circ} \mathrm{BTDC}$

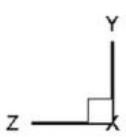

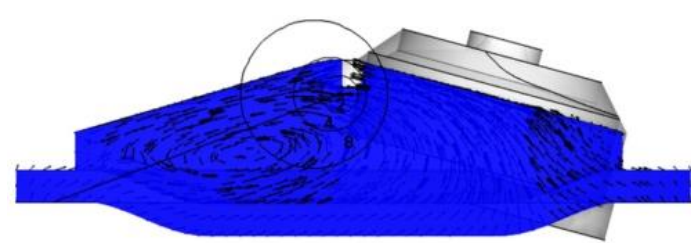

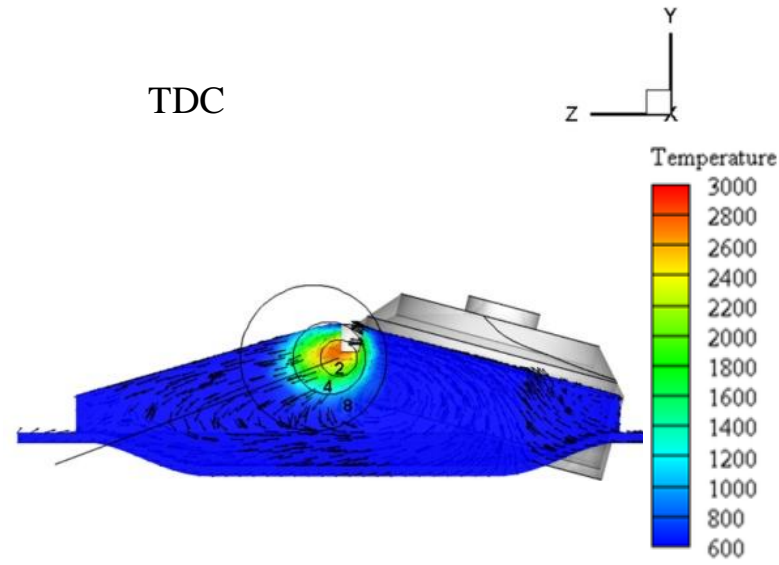

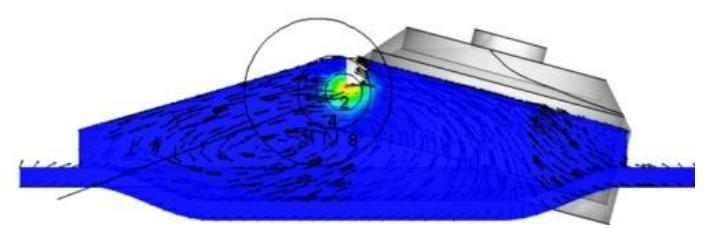

$10^{\circ} \mathrm{ATDC}$

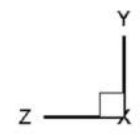

Figure 12. Flame propagation for $\mathrm{CNG}$ ignition $340^{\circ}$ BTDC to $10^{\circ}$ ATDC.

\section{CONCLUSIONS}

Engine operation with conventional bi-fuel CNG kit has detrimental effects at low and high speed engine operations. The burn curve shows that the CNG has slow burning due to the engine design, which was meant for gasoline performance. The best engine operation occurred at $4000 \mathrm{rpm}$, but a loss of pressure leads to volumetric losses. However, the CFD model produced higher mass fraction burn due to assumptions made about the heat transfer. These errors were due to heat transfer, crevice volume, and pressure losses which were in the ideal condition in CFD. However, the CFD model was able to predict the flame propagation speed at $8.45 \mathrm{~m} / \mathrm{s}$. Since equipment development for in-cylinder flame speed measurement has been expensive, the results presented herein enable the research to progress more cost-effectively. A CFD simulation of gasoline will be used to continue to compare the values between CNG and gasoline. There is room for improvement in terms of turbulence, as well as spark timing and the air fuel ratio.

\section{ACKNOWLEDGEMENTS}

The authors would like to thank the Faculty of Mechanical Engineering in Universiti Sains Malaysia (USM) and MOSTI for financial support under MOSTI science fund 
(Optimization Of Combustion For Compressed Natural Gas (CNG) Fuel Engine: 6013388).

\section{REFERENCES}

[1] EPA US. Light-duty automotive technology, carbon dioxide emissions, and fuel economy trends: 1975 Through 2010. EPA's Annual Report. 2013;1001:48105.

[2] Choo S, Mokhtarian PL. What type of vehicle do people drive? The role of attitude and lifestyle in influencing vehicle type choice. Transportation Research Part A: Policy and Practice. 2004;38:201-22.

[3] Ramasamy D, Yuan GC, Abu Bakar R, Zainal ZA. Validation of road load characteristic of a sub-compact vehicle by engine operation. International Journal of Automotive and Mechanical Engineering. 2014;9:1820-31.

[4] Shamsudeen A, Abdullah S, Ariffin AK, Rasani MRM, Ali Y. Design and simulation of a cylinder head structure for a compressed natural gas direct injection engine. International Journal of Automotive and Mechanical Engineering. 2014;9:1620-9.

[5] Lloyd B, Subbarao S. Development challenges under the Clean Development Mechanism (CDM) - Can renewable energy initiatives be put in place before peak oil? Energy Policy. 2009;37:237-45.

[6] Kamil M, Rahman MM, Bakar RA. Performance evaluation of external mixture formation strategy in hydrogen fueled engine. Journal of Mechanical Engineering and Sciences. 2011;1:87-98.

[7] Kamil M, Rahman MM, Bakar RA. Integrated simulation model for composition and properties of gases in hydrogen fueled engine. International Journal of Automotive and Mechanical Engineering. 2013;8:1242-155.

[8] Kamil M, Rahman MM, Bakar RA. An integrated model for predicting engine friction losses in internal combustion engines. International Journal of Automotive and Mechanical Engineering. 2014;9:1695-708.

[9] Johnstone N, Karousakis K. Economic incentives to reduce pollution from road transport: the case for vehicle characteristics taxes. Transport Policy. 1999;6:99108.

[10] Dincer I. Renewable energy and sustainable development: a crucial review. Renewable and Sustainable Energy Reviews. 2000;4:157-75.

[11] Lapidus AI, Krylov IF, Tonkonogov BP. Natural gas as motor fuel. Chemistry and Technology of Fuels and Oils. 2005;41:165-74.

[12] Yusaf T, Baker P, Hamawand I, Noor MM. Effect of compressed natural gas mixing on the engine performance and emissions. International Journal of Automotive and Mechanical Engineering. 2013;8:1416-29.

[13] Aziz A, Rashid A, Firmansyah, Shahzad R. Combustion analysis of a CNG direct injection spark ignition engine. International Journal of Automotive and Mechanical Engineering. 2010;2:157-70.

[14] Ramasamy D, Bakar RA, Rahim MF, Group AF. Comparative evaluation of a two stroke compressed natural gas mixer design using simulation and experimental techniques. Proceedings of the Fourth IASTED International COnference, Power and Energy Systems, 2008:359-62.

[15] Aslam MU, Masjuki HH, Kalam MA, Abdesselam H, Mahlia TMI, Amalina MA. An experimental investigation of $\mathrm{CNG}$ as an alternative fuel for a retrofitted gasoline vehicle. Fuel. 2006;85:717-24. 
[16] Amr Ibrahim SB. Optimization of a natural gas SI engine employing EGR strategy using a two-zone combustion model. Fuel. 2008;87:1824-34.

[17] Khalid Abdul Rahim AL. Oil and gas trends and implications in Malaysia. Energy Policy. 2012;50:262-71.

[18] Kapilan N, Ashok Babu TP, Reddy RP. Improvement of performance of dual fuel engine operated at part load. International Journal of Automotive and Mechanical Engineering. 2010;2:200-10.

[19] Smits JJM. Modeling of a fluid flow in an internal combustion engine. Eindhoven University of Technology, 2006; 1-97.

[20] Agilent T. Agilent U2500A Series USB simultaneous sampling multifunction data acquisition devices. User's Guide. 2012.

[21] Surface vehicle standard. SAE International, Warrendale, PA, USA, 2004.

[22] Pourkhesalian AM, Shamekhi AH, Salimi F. Alternative fuel and gasoline in an SI engine: A comparative study of performance and emissions characteristics. Fuel. 2010;89:1056-63.

[23] Wang Y. Air flow effects in the piston ring pack and their implications on oil transport: Massachusetts Institute of Technology; 2012.

[24] Wright CW, White JJ. Development and validation of a snowmobile engine emission test procedure. SAE Technical Paper NO. 982017; 1998.

[25] Dhaliwal B, Checkel D. Tailpipe emissions comparison between propane and natural gas forklifts. SAE Technical Paper No. 2000-01-1865; 2000.

[26] Cho HM, He B-Q. Spark ignition natural gas engines-A review. Energy Conversion and Management. 2007;48:608-18.

[27] Gray C. A review of variable engine valve timing. SAE Technical Paper NO. 880386; 1988.

[28] Ramadhas A, Muraleedharan C, Jayaraj S. Performance and emission evaluation of a diesel engine fueled with methyl esters of rubber seed oil. Renewable Energy. 2005;30:1789-800.

[29] Herweg R, Maly R. A fundamental model for flame kernel formation in SI engines. SAE Technical Paper No. 922243; 1992. 